ISSN 0001-6002/2001/43/3/101-102

Acta Médica Costarricense,(C2001

Colegio de Médicos y Cirujanos

Editoriales

\title{
Resistencia bacteriana a antibióticos
}

Los antibióticos son productos del metabolismo secundario de diversos microorganismos del suelo que participan en procesos ecológicos de competencia por nichos nutricionales y representan un ejemplo de diferenciación y especialización microbiana. Es obvio que los microorganismos productores de antibióticos también posean mecanismos de resistencia a los mismos antibióticos que producen. Paralelamente, en esta competencia dinámica, otros microorganismos han desarrollado sus propios mecanismos de resistencia o los han adquirido directamente de los microorganismos productores de antibióticos. La capacidad de producir antibióticos y los mecanismos de resistencia por parte de los microorganismos son, entonces, el resultado de un intenso proceso evolutivo ocurrido durante miles de millones de años en la naturaleza. ${ }^{1}$

Desde su introducción como drogas hace unos sesenta años, los agentes quimioterapéuticos antimicrobianos, incluyendo antibióticos, algunos naturales y otros semisintéticos, y otros agentes sintéticos como las sulfonamidas y las quinolonas, han jugado un papel esencial, junto con medidas preventivas como la vacunación, en la disminución de la morbilidad y la mortalidad causadas por las enfermedades infecciosas. Sin embargo, el amplio uso, mal uso y abuso de los antibióticos, no solamente en el tratamiento y la prevención de infecciones bacterianas en el ser humano, sino también en medicina veterinaria, como promotores de crecimiento en la producción animal y en agricultura, han ejercido una inmensa presión de selección para el surgimiento y la diseminación de los mecanismos de resistencia entre diversas poblaciones bacterianas.

La diseminación de estos mecanismos de resistencia no conoce barreras geográficas, biológicas ni sociales. Actualmente, la letalidad de muchas infecciones causadas por bacterias multirresistentes es similar a la observada antes de la introducción de los antibióticos como agentes terapéuticos y se ha acuñado, incluso, el concepto de "era post-antibiótica. ${ }^{1,2}$ La Organización Mundial de la Salud ha reconocido la situación de la pérdida de eficacia de los tratamientos con antibióticos y ha propuesto una estrategia global para enfrentar el problema. ${ }^{3}$

Uno de los elementos fundamentales es el desarrollo de una estrategia es la vigilancia de los perfiles de resistencia bacteriana y recopilación de información en forma sistemática. Esta información resulta esencial, no solamente para determinar la magnitud del problema, identificar los principales microorganismos responsables de infecciones intrahospitalarias, identificar la utilidad real de los diversos antibióticos de mayor uso en la seguridad social, sino también,, para poder definir líneas de acción y estrategias en el uso de antibióticos en un futuro inmediato.
En este número Ricardo Boza y Edith Barrantes del Hospital San Juan de Dios publican algunos resultados sobre los perfiles de resistencia bacteriana a los antibióticos en el período 1995-1999, ${ }^{4}$ lo cual constituye un ejemplo a seguir por otras instituciones prestadoras de servicios de salud en nuestro país e incluso en la región. Varios aspectos en este trabajo deben ser destacados. En primer lugar, se realizó una adecuada selección de los microorganismos a vigilar, incluyendo tanto bacterias Gram-positivas (Staphylococcus aureus, Staphylococcus epidermidis, Streptococcus pneumoniae y Enterococcus) como Gram-negativas (Escherichia coli, Klebsiella pneumoniae, Enterobacter cloacae, Pseudomonas aeruginosa y Acinetobacter baumannii [calcoaceticus]). En segundo lugar, los perfiles de resistencia están establecidos con base a los patrones de uso de antibióticos de la Caja Costarricense de Seguro Social. En tercer lugar, se contó con un sistema automatizado para la identificación de las especies, la determinación de los perfiles de resistencia y la recopilación sistemática de la información.

Los resultados de este artículo son importantes. En términos generales, existe una clara tendencia de incremento de los perfiles de resistencia en todas las bacterias estudiadas, con excepción de Streptococcus pneumoniae, lo que irremediablemente conducirá a una pérdida en la eficacia de los tratamientos con antibióticos actuales y a la necesidad de incorporar antibióticos de mayor costo en el esquema de la institución. Sin duda, es preocupante el incremento constante en la resistencia a antibióticos B-lactámicos en bacterias Gram-positivas, particularmente a la oxacilina en Staphylococcus, así como a amikacina, ceftazidima, cefotaxime y ciprofloxacina en bacilos Gram-negativos y, muy especialmente, la resistencia a imipenem en Pseudomonas aeruginosa y Acinetobacter baumannii.

Otro aspecto de relevancia es señalado por este artículo: la necesidad de implementar metodologías en los laboratorios clínicos para la detección de mecanismos de resistencia que no lo son mediante los sistemas automatizados o los métodos de rutina. En este punto se destaca la necesidad de estudiar con mayor detalle la producción de ß-lactamasas de espectro ampliado en bacterias Gram-negativas, particularmente en especies de Klebsiella, Enterobacter y otras de la familia Enterobacteriaceae, y la resistencia a vancomicina en Enterococcus y Staphylococcus.

Es muy probable que otras instituciones prestadoras de servicios de salud enfrenten una situación muy similar a la descrita en este artículo. Solamente con este tipo de estudio 
podremos tener un panorama completo del problema de la resistencia a los antibióticos en nuestras instituciones y en las comunidades y así poder explorar las estrategias para encontrar soluciones que tiendan a disminuir su impacto en el estado de salud de los habitantes de nuestro país y de la región.

\section{Fernando García \\ Centro de Investigación en Enfermedades \\ Tropicales, Facultad de Microbiología \\ Universidad de Costa Rica \\ Correo electrónico: fgarcia@cariari.ucr.ac.cr}

\section{Referencias}

1. Levy SB. The antibiotic paradox: how the miracle drugs are destroying the miracle. Plenum Press, New York. 1992: 90.

2. Cohen ML. Epidemiology of drug resistance: implications for a postantimicrobial era. Science 1992; 257: 1050-1055.

3. World Health Organization. Containing antimicrobial resistance:review of the literature and report of a WHO workshop on the development of a global strategy for the containment of antimicrobial resistance. 1999.

4. Boza R, Barrantes E. Resistencia bacteriana a antibióticos en el Hospital San Juan de Dios 1995-1999. Acta Med Costarric 2001; 43: 119-127. 